\title{
Analysis of Food Poisoning in DKI Jakarta 2016 (Indonesian National Agency Drug and Food Control)
}

\author{
Fatikhatul Mabruroh ${ }^{1}$ \\ Department of Epidemiology \\ Major of Public Health, Faculty of Medicine and Health \\ Science \\ UIN Syarif Hidayatullah \\ Jakarta, Indonesia \\ Fatikhatul.mabruroh13@mhs.uinjkt.ac.id
}

\author{
Ratri Ciptaningtyas ${ }^{2}$ \\ Department of Nutritional Health \\ Major of Public Health, Faculty of Medicine and Health \\ Science \\ UIN Syarif Hidayatullah \\ Ratri.ciptaningtyas@uinjkt.ac.id
}

\begin{abstract}
Food poisoning is a public health problem in Indonesia. DKI Jakarta is one of the provinces that has a higher number of cases and reports completeness than other provinces ie 213 cases and $94.6 \%$ respectively. INADFC which is the source of data in this study has done an analysis of existing data, but only up to the descriptive analysis. The purpose of this study was to analyze the food poisoning analytics in DKI Jakarta in 2016 using the report of food poisoning from INADFC.The study design in this study was cross-sectional with quantitative approach. The sample size was 208 cases by applying inclusion criteria. The strength of the test used is $95 \%$ obtained from the calculation of the hypothesis test formula of two proportions. The analytical analysis used is multinomial logistic regression test.

The results of this study indicate that food poisoning occurs in the optimum immune age group $(\mathbf{9 2 . 3 \%})$, females $(51.4 \%)$ and in the dry season $(62 \%)$. While the type of food that causes food poisoning is seafood and fishes $(52.4 \%)$ with the source of poisoning is the household $(\mathbf{4 6 . 2 \%})$. In the multinomial logistic regression test results, only sex was associated with food poisoning sources $(P$ value $<0.05)$. The results of this study are expected to be input to INADFC in determining the prevention of food poisoning in Indonesia.
\end{abstract}

Keywords - Food Poisoning; immunity status; sex; season

\section{INTRODUCTION}

Globally the disease caused by food is reported to increase significantly each year. According to WHO, more than $50 \%$ of diarrhoea cases are caused by contaminated food and cause 550 million sick people and 230,000 deaths. 125,000 occur in children under 5 years [1-3]. Africa and Southeast Asia are regions with high incidence and high mortality rates in food diseases [2]. And developing countries have 4 times higher risk than developed countries in food poisoning [4].

According to the National Poisoning Information Centerof the Indonesian Agency for Drug and Food Control (INADFC), food poisoning in Indonesia based on case reports since 2014 tends to fluctuate. Some of the factors identified to contribute to food poisoning are lack of self-hygiene food handlers and poor water and environmental supplies [1]. But according to other studies, food handlers are a major cause of contamination because they can spread harmful organisms through skin lesions or fecal-oral [5, 6]. Kitchen conditions and production equipment also affect the occurrence of contamination in food [1]. However, several other studies also suggest that food poisoning is also influenced by demographic factors such as gender, age, marital status and economic status [7].

Food poisoning is a public health problem that needs to be addressed as early as possible. However, to formulate such mitigation efforts can be made if available data and information resulting from the implementation of monitoring or continuous surveillance [8]. INADFCis one of the government agencies that have national food poisoning data obtained from hospital reports voluntarily. INADFChas collected data on food poisoning since 2001, but only in 2016 the data tends to be complete than the previous year where the feasibility of the data to be studied is $97.65 \%$.

Reports obtained from 34 provinces where Daerah Khusus Ibukota (DKI) Jakarta has 213 cases with $94.6 \%$ data completeness. Based on the number of cases and the completeness of the data, DKI Jakarta becomes the province which becomes the research priority. In addition, INADFChas conducted an analysis of the data of food poisoning received. But it is limited to the descriptive analysis of each variable obtained. While analytic analysis of food poisoning has not been done. So that based on the description, this study aims to perform analytical analysis of food poisoning in DKI Jakarta in 2016 using food poisoning data INADFC.

\section{METHOD}

This research was conducted in DKI Jakarta on May until August 2017 using data from INADFC. The study design used was cross-sectional with quantitative approach. The sample used in this study was 208 people with $95 \%$ test strength. The analysis used is descriptive and analytic analysis (multinomial logistic regression) to determine the relationship between gender and season variables to the source of food poisoning. However, on secondary data owned there are some outcome cells that have data too small or zero. So to minimize the existence of errors (warning message) on the results of an analytical analysis, the researchers did not include age variables as well as grouping the dependent variable into 5 categories (previous> 5). Thus it will reduce the number of cells that have a value too small or zero. 
III. RESULT

\section{A. Descriptive analysis}

TABLE 1

PROPORTION OF AGE, SEX, SEASON, TYPE OF FOOD AND SOURCE OF POISONING IN JAKARTA 2016

\begin{tabular}{|l|l|l|}
\hline Variable & Total (n) & Proportion (\%) \\
\hline Age (years) & 16 & 7.7 \\
\hline$<6$ and $>59$ & 192 & 92.3 \\
\hline $6-59$ & 101 & 48.6 \\
\hline Sex & 107 & 51.4 \\
\hline Male & \multicolumn{2}{l|}{} \\
\hline Female & 62 \\
\hline Season & 79 & 38 \\
\hline Dry & \multicolumn{2}{|l|}{} \\
\hline Wet & 109 & 52.4 \\
\hline Type of foods & 3 & 1.4 \\
\hline Seafood, fishes & 4 & 1.9 \\
\hline Vegetables & 5 & 2.4 \\
\hline Instant noodles & 10 & 4.8 \\
\hline Non-poultry meat & 8 & 3.8 \\
\hline Poultry & 32 & 15.4 \\
\hline Rice, & 15 & 7.2 \\
\hline Multiple food & 7 & 3.4 \\
\hline Gorengan, meatball & 8 & 3.8 \\
\hline Jengkol & 1 & 5 \\
\hline Snack & 6 & 2.9 \\
\hline The others & \\
\hline Unknown & 96 & 46.2 \\
\hline Sources of Food Poisoning & 32.7 \\
\hline Household & 68 & 12.5 \\
\hline Catering services & 26 & 5.3 \\
\hline Food street & 11 & 3.4 \\
\hline The others & 7 & \\
\hline Unknown &
\end{tabular}

Food poisoning in DKI Jakarta in 2016 occurs mostly in the age group with optimal immunity level (6 - 59 years) $(92.3 \%)$ and female sex $(51.4 \%)$. Meanwhile, according to the season, food poisoning in DKI Jakarta mostly happened in the dry season $(62 \%)$. Types of food that causes food poisoning are seafood and fish (52.4\%) and food poisoning sources are mostly sourced from household processed food.

\section{B. Analytical analysis}

TABLE 2

SEX AND SEASONAL RELATIONSHIP TO FOOD POISONING SOURCE IN DKI JAKARTA 2016

\begin{tabular}{|l|l|l|l|l|l|}
\hline Variable & $\begin{array}{c}\text { Total } \\
(\mathbf{n})\end{array}$ & $\begin{array}{c}\text { Proportion } \\
(\%)\end{array}$ & $\begin{array}{c}\text { P } \\
\text { value }\end{array}$ & OR & \multirow{2}{*}{ 95\% CI } \\
\hline \multicolumn{7}{|c|}{ Household } \\
\hline Sex \\
\hline Male & 101 & 48.6 & 0.294 & 2.294 & $0.454,13.588$ \\
\hline Female & 107 & 51.4 & \multicolumn{3}{|c|}{ Reference group } \\
\hline Season \\
\hline Wet & 79 & 38 & 0.721 & 0.751 & $0.157,3.604$ \\
\hline Dry & 129 & 62 & \multicolumn{3}{|c|}{ Reference group } \\
\hline
\end{tabular}

Catering sevices

\begin{tabular}{|c|c|c|c|c|c|}
\hline \multicolumn{6}{|l|}{ Sex } \\
\hline Male & 101 & 48.6 & 0.474 & 1.876 & $0.335,10.505$ \\
\hline Female & 107 & 51.4 & \multicolumn{3}{|c|}{ Reference group } \\
\hline \multicolumn{6}{|l|}{ Season } \\
\hline Wet & 79 & 38 & 0.469 & 0.554 & $0.112,2.735$ \\
\hline Dry & 129 & 62 & \multicolumn{3}{|c|}{ Reference group } \\
\hline \multicolumn{6}{|c|}{ Street Food } \\
\hline \multicolumn{6}{|l|}{ Sex } \\
\hline Male & 101 & 48.6 & 0.195 & 3.394 & $0.539,20.816$ \\
\hline Female & 107 & 51.4 & \multicolumn{3}{|c|}{ Reference group } \\
\hline \multicolumn{6}{|l|}{ Season } \\
\hline Wet & 79 & 38 & 0.868 & 1.155 & $0.210,6.334$ \\
\hline Dry & 129 & 62 & \multicolumn{3}{|c|}{ Reference group } \\
\hline \multicolumn{6}{|c|}{ The others } \\
\hline \multicolumn{6}{|l|}{ Sex } \\
\hline Male & 101 & 48.6 & 0.034 & 11.47 & $1.201,109.692$ \\
\hline Female & 107 & 51.4 & \multicolumn{3}{|c|}{ Reference group } \\
\hline \multicolumn{6}{|l|}{ Season } \\
\hline Wet & 79 & 38 & 0.870 & 0.851 & $0.121,5.955$ \\
\hline Dry & 129 & 62 & \multicolumn{3}{|c|}{ Reference group } \\
\hline
\end{tabular}

Analytical analysis using multinomial logistic regression analysis showed no relationship ( $\mathrm{P}$ value> 0.05 ) between the season with household, catering service, street vendors, etc. as food poisoning source in DKI Jakarta 2016. And only sex having a relationship (P-value 0.034 ) with others as a source of food poisoning, while sex with household sources, catering and street vendors have no relationship.

\section{DISCUSSION}

A. Age

The results of this study indicate food poisoning in DKI Jakarta experienced by many individuals aged 6 - 59 years with a proportion of $92.3 \%$. Age 6 - 59 years old is an age group that has an optimal immune status in which the immune system has developed well and is able to fight pathogens or foreign bodies that infect the body. While aged less than 6 years and more than 59 years old is a group that has a low immunity status.

The results of this study are similar to the results of research conducted in Zimbabwe and Egypt by Teschke (2010), Abd-Elhaleem (2011) and Gumbo (2015) that food poisoning is also experienced by groups aged 6 - 59 years (9-12). However, unlike other research conducted by Majowicz (2004), Kariuki (2008), Abd - Elhaleem (2011), Painter (2013), and Pardhan - Ali (2017) where food poisoning experienced by many age group less than 10 years and more than 60 years (1114).

The existence of variations between the results of this study and some previous studies indicate a factor other than the body's immune system. In the age group of 6 - 59 years, individuals tend to have many activities that create a variety of contacts with other humans or goods in the neighborhood. According to Tood (2010) in Abd-Elhaleem (2011) along with increased activity usually, contamination of fingers will also increase such as the use of toilets, touching the nose, touching 
other objects or touching raw food which usually still contains many pathogens.

At school age, children who are unfamiliar with good hygiene and the environment will tend to behave less well. Like not washing hands before eating and playing and not washing hands after using the toilet. The Grenade study found that $11.9 \%$ of high school students never or rarely washed hands before eating and $3.7 \%$ never or rarely washed their hands after using the toilet [15].

As for the optimal immunity group, there are also groups who have status as workers and parents. Workers have a high level of mobility and difficult to maintain personal hygiene, especially hand hygiene before and after eating food. In Indonesia alone, not all places provide running water and soap to wash hands. so that it increases the chances of individuals to experience food poisoning. While parents have a duty to care and nurture children are also at high risk for food poisoning. School-age children who are likely to have low knowledge of hygiene may also increase the risk to themselves and others. This is in accordance with the opinion of PardhanAli (2017), the presence of parent contacts on small children, especially infants will increase the risk of infection in the elderly. However, it is certain if the child is in a pattern of parenting with poor hygiene [16].

High food poisoning that occurred at the age of $6-59$ years can also be caused due to high reports of food poisoning in the age group. Adults have been able to behave independently to seek treatment and not to rely on others as well as toddlers or elderly [16]. As well as the condition of DKI Jakarta as an urban area dominated by large cities/regencies and equipped by public facilities that facilitate the public to access healthcare facilities.

Of course with the high search behavior of these medicines cause food poisoning cases can be recorded well in health facilities, especially hospitals. But in DKI Jakarta, health facilities are not only hospitals where the INADFC get poisoning data. But there are also Public Health Centers (Puskesmas), private health clinics owned by doctors as well as other health workers as well as other medical personnel who open the practice without clinics that do not report food poisoning to the INADFC. So there is still the possibility of many cases of food poisoning in the community that is not recorded in the hospital

\section{B. Sex}

The results of this study indicate that sex is unrelated $(\mathrm{P}$ value> 0.05) with food poisoning in DKI Jakarta in 2016. However, looking at other research conducted by Majowicz (2004) and Abd-Elhaleem (2011) significantly related to food poisoning ( $\mathrm{P}$-value <0.05) $(11,12)$. In addition, univariate analysis results in this study, the proportion of food poisoning more experienced by women than men. The same is revealed in previous studies where women were more likely to experience food poisoning with a proportion of $50.4 \%-71.4 \%$ than male $\operatorname{sex}(9-11)$.

In Indonesian society, women who are 26-45 years old usually have status as parents. Especially mothers who make more contacts such as kissing, making skin contact and changing diapers. The contact can be risky if the mother does not wash hands after changing diapers. Then unconsciously the mother made contact with food. According to Pardhan-ali (2017), direct contact of mothers with children under five may increase the risk of food poisoning in mothers. In addition, according to Scott, Salmonella infection by one family member, especially young children who still have a body immunity that has not been optimal can cause other family members infected with the same disease [17].

In addition, the results of this study female sex food poisoning caused by eating seafood and fishes with the proportion of $59.8 \%$. As in previous studies using Centers for Disease Control and Prevention's (CDC) data from 2006-2007 where women ate more raw fish than men but in the study had $\mathrm{P}$ value ( $\mathrm{P}$ value) $>0.01$ [18]. Other studies have also revealed the same in which female sex consumes more than $12.5 \%$ of raw shellfish compared to males $(6.8 \%)$ [18].

As in the world of women's health often get special attention because in life there are several different phases than men. Therefore women are encouraged to consume some types of food as well as special supplements such as tablets plus blood and seafood and fish - fish. Compared to beef and goat, fish and the like is food that has a relatively cheap price, so the possibility of people to consume fish is much greater.

According to previous research, fish and seafood are the of animal nutrition that can provide omega - 3 fatty acids that are good for fetal neural development and women are encouraged to eat two more fish than men so that it causes more women food poisoning due to fish consumption $(19,20)$.

Other factors that contribute to food poisoning are the behaviors and habits possessed by each gender. As well as poor hygiene on consumers and food handlers (food handler) is also a major factor in food poisoning. such as the habit of washing hands after touching raw food has not become a community habit. In China, new cases and food poisoning pains are mostly caused by unclean practices of $56.6 \%$ and $64 \%$ [21].

In addition, bad habits to store improper food is still often done in the household. According Malangu, people do not consider the house as a potential source of food poisoning. In India, $63 \%$ of households store non-vegetarian food at room temperature and only $29.4 \%$ consume food directly after cooking [22]. Another bad habit that can be found in households is to reheat the cooked food that has been stored. Inadequate storage can affect organisms grow and multiply. The breeding organisms will die through a reheating process with a high enough temperature and for a long time. But in toxin-producing bacteria, the heating process cannot inhibit the toxins that have contaminated the food. The toxin-producing bacteria are Bacillus cereus which produces the emetic toxin (cereulide) which can still cause toxicity and cannot be lost through by heating process [23]. In addition, the spores formed cannot be eliminated through heating, acidification, pasteurization or sanitation procedures [24].

The poor environmental sanitation is also a place to live the pathogen organisms breed. Some pathogens can survive in an environment that looks clean but is actually dirty. The 
environment is usually cleaned but does not use a disinfectant so there are still some bacteria or organisms.

According to Mensah (2002), diarrhea-causing pathogens can be found in 11 of the 78 mothers who have washed hands and the pathogens can certainly be transmitted to other people, especially young children. Whereas in Thailand of children suffering from diarrhea due to enterotoxigenic E. coli (ETEC) was detected 6 of 42 mothers and 37 of 50 children had ETEC on their hands [25].

The use of cutlery also reduces the level of contamination compared with using the hands directly when eating. Similarly, when preparing and cooking the use of cooking utensils and not using hands directly can reduce the risk of contamination [25]. The same is expressed by Malangu where tableware is not a major source of pathogens [26]. Some people in Indonesia have a habit of eating by hand when consuming various types of food that is not berkuah. It is considered practical and can add flavor to the food. The habit is also done by some people of DKI Jakarta.

While in other studies mentioned the gender of men have a better knowledge than women in terms of food security $(27,28)$. On the contrary, the activity related to food is mostly done by women who have lower knowledge. Knowledge possessed by individuals will tend to influence the form of individual behavior. These activities also cause women more risk than men. According to Lund (2011) and Indranil (2016), the high intensity of contact with food can risk food poisoning to oneself and the environment.

Food poisoning that often occurs in households is also likely caused by the use of pesticides to repel insect bugs. Because improper food storage causes particles of pesticide substances that have been dispersed in the space to fall into the food. In India, 60 men aged 20-30 years experience food poisoning after eating cooked food in the soup kitchen. After the investigation is known the cause is the use of pesticides containing organophosphate malathion in the morning to repel insects. However, the pesticide particles contaminate the food stored in the open. Of the 60 individuals who ate the food were all poisoned [22].

In addition to food poisoning that occurred due to unintentional behavior, but did not deny there are also some cases of food poisoning intentionally and planned. As in Nigeria food poisoning is closely related to a crime that one means to a victim [26]. In China, the abuse of toxic substances in food resulted in pain of $2.9 \%$ (2930 cases) while causing new cases of food poisoning $6.7 \%$ (161 cases) [21]

\section{Season}

Food poisoning research in DKI Jakarta in 2016 shows that seasons have no relationship ( $\mathrm{P}$ value) with food poisoning sources from households, catering, street vendors, others and unknown sources. The results of this study differ from the results of other studies that season has a significant relationship in food poisoning caused by Campylobacter and Salmonella typhimurium, Salmonella enteridis with P-value $<0.01[29,30]$. However, looking back at the results of descriptive analysis of the proportion of food poisoning in DKI Jakarta in 2016 occurred in the dry season with proportion $62 \%$, while the proportion of food poisoning during the rainy season was $38 \%$. Similarly, in other studies, food poisoning occurred during the dry season with a proportion of $26.7 \%$ and $25.6 \%$, respectively. The same is true of research conducted in Grenade where there is an increase in cases of diarrhea and vomiting in the dry season $[4,10,15]$.

In the dry season, the volume of water decreases compared to the rainy season. This is due to the reduced rain intensity. Reduced volumes of water unconsciously affect individual behavior in maintaining personal hygiene. So individuals will skimp on using water either to wash their hands after using the toilet, touching food, after or before eating food. In individuals who already wash the hands can still be found pathogenic organisms. In other words, individuals who do not wash their hands or just wash their hands only with water without using soap will have a higher risk than individuals who wash their hands.

As in the laboratory testing of food handlers conducted in previous research is on the hand swab test. found $60 \%$ and $100 \%$ of Staphylococcus aureus bacteria on hands and nails respectively [9]. Meanwhile, according to Mensah (2002), diarrheal pathogens were found in 11 of the 78 mothers who had washed their hands. And in children with diarrhea, 6 of 42 mothers and 37 of 50 children found enterotoxigenic E. coli (ETEC) in their hands.

Other activities favored by some families are grilling (barbecuing) meat, seafood, and fish - fish in the home environment. Types of food that is often cooked by roasting are meat, seafood, and fish - fish. While the baking process itself is actually an inadequate cooking process. Because it has not reached the optimum temperature required to kill pathogenic organisms. Although from seafood skin, fish - fish, and meat already look ripe. In fact, the inside of these types of food has not been cooked perfectly. And if consumed will lead to the clinical manifestation of symptoms of food poisoning such as nausea, vomiting, diarrhea and so forth.

It is certainly riskier if it occurs in tropical climates that have optimum temperatures and humidity for pathogenic organisms to grow and multiply like Campylobacteriosis and Salmonella serogroup D [31]. According to previous research, in some cases of food poisoning when hygiene practices are not considered food will be a medium for the reproduction of organisms in tropical climatic conditions [32]. This assumption is similar to the results of a Canadian study that Campylobacteriosis and Salmonellosis have a P-value significance of less than 0.05 and tend to occur in late summer and early autumn [16].

But in this study cannot be known the type of pathogen that causes food poisoning that can later be associated with environmental factors due to data limitations. So that efforts can be made to improve the report is the national INADFC coordinate with INADFC in each province as a form of decentralized health. Provincial INADFC can conduct direct hospital investigation into cases of food poisoning. Another advantage gained is that it can perform sampling required for laboratory test. 


\section{Type of Foods}

Food poisoning in DKI Jakarta in 2016 is mostly due to the consumption of seafood and fish - the fish with the proportion of $52.4 \%$ of the 208 cases of food poisoning. Seafood and fish - fish themselves are animals that live in water such as crabs, shellfish, shrimp, all types of fish and so forth. Basically seafood and fish is a source of nutrition needed by the body, but under certain conditions such as improper behavior in processing or personal hygiene that is not good can change the function of seafood and fish - fish into vector disease.

One of these behaviors is the habit of the community in processing fish by burning or eating fish in a raw state. Surely processing such as burned, smoked or served in a raw state will increase the risk of food poisoning. Because the actual processing process is not including adequate food processing where it must reach a certain temperature. According to some experts, the recommended temperature in fish processing is $62.8^{\circ} \mathrm{C}-74^{\circ} \mathrm{C}[33,34]$.

It is also supported by other studies where inadequate treatment of fish may cause food poisoning [35]. And some of the pathogens to be found are Salmonella, Shigella spp., Clostridium botulinum, Staphylococcus aureus, Clostridium perfringens, $C$. diversus, $E . \quad$ coli, $C$. luteola, $P$. fluorescens/putida, E. sakazakii, C. diversus/amalonatica, K. pneumonia and Bacillus aureus. Some viruses also become infected with fish such as Norovirus, and Hepatitis A. These types of parasites include worms and protozoa. While in the fish that processed only marinated or smoked can be found bacteria C. Botulinum, and on the shell - the shellfish bacteria are often found are Salmonella typhi and Salmonella paratyphi. $[34,36]$. Therefore, uncooked fish and seafood consumption should be avoided as some of these organisms still exist and continue to breed if they are present in the right environment.

Similarly, that occurred in the United States in 1983 . 1992 and resulted in $99 \%$ deaths due to seafood consumption as the third most common cause of food poisoning [37]. In addition to containing pathogens that are the reason fish as a cause of food poisoning is in some types of fish found chemicals that are harmful to human health.

Such chemicals such as scromboid and ciguatera toxin. Food poisoning due to scromboid toxin indicates the consumption of fish that have high histamine levels. Histamine intoxication is caused by fresh or burned fish consumption and improper processing and storage. Examples of high fish histamine are tuna, mackerel, marlin, escolar fish, mahi - mahi and mackerel fish. Histamine is a product of histidine decarboxylation in the muscle of fish and is induced by gramnegative bacteria living in the fish lining tract [38]. While the poison ciguatera produced by algae in fish such as red snapper Gambierdiscus toxicus. Where a person with poisoning ciguatera will experience symptoms of nausea, vomiting, symptoms that attack other nerves such as tingling on a finger that persists for several days to years $[35,39]$. There are also other fish that also poison like a bloated fish that produce bloated toxins. And some types of shells also produce toxins that attack the nervous system [35].

In addition to risky behavior in the community, fish habitat as a seafood environment and fish - fish also affect the condition of seafood and fish. Dirty environments such as excavated pits or streams of feces, rivers or seas where waste disposal, waste polluted seas etc. can contaminate the seafood and fish bodies that feed human beings. In some developing countries such as Indonesia, disposal of waste from industries tends not to be properly processed, so industrial waste is toxic and pollutes the environment. One of the chemicals that pollute the environment is mercury. The contaminated environment forms the accumulation of pathogenic, toxic or other dangerous concentrations in the fish body continuously.

According to Maruyama (2012) individuals who ate fish with high levels of methylmercury (approximately $200 \mathrm{~g} /$ liter) were associated with nerve damage in cases of food poisoning outbreaks that occurred in Japan and Iraq [40]. And there are outbreaks of food poisoning caused by the consumption of seafood containing calicivirus, hepatitis A virus and Salmonella enterica serotype typhi [34]. However, according to Painter (2013), food poisoning due to consumption of fish found $60 \%$ of biotoxin especially poison ciguatera, while the oysters found $\mathrm{V}$. vulnivicus bacteria.

However, there is a difference with the research done in United State where food poisoning cases that cause patients to undergo hospital treatment, $46 \%$ caused by consumption of animal products such as poultry, eggs, beef or other animal flesh. While $41 \%$ is caused by consumption of plant products such as leafy vegetables, fruits, vegetable oils or other plant products and $6 \%$ for eating fishes and seafood. In addition, food poisoning can also cause death. Approximately 629 cases of death each year are caused by consumption of animal products $(43 \%)$, plant products $(25 \%)$ and fish and seafood (6\%) [14]

Then the type of food that causes most food poisoning in DKI Jakarta in 2016 after seafood and fish - fish is multiple foods with $15.4 \%$ proportion. While vegetables, instant noodles, and food types are not known to have a small proportion.

The existence of unknown food type is caused by the condition of patients who do not know or do not remember the type of food that has been consumed in a few hours until a few days ago. In addition, other causes are health workers at the Emergency Department (IGD) who do not complete the medical records of cases of poisoning, especially in the food poisoning. Thus should the health officer should dig the information to avoid missing data to the patient but still pay attention to the condition of the patient. Or can also do it to family or friends who are the patient poisoning food.

In addition to food poisoning conditions as in this study, there is also another condition that is Extraordinary Events (KLB) which according to Regulation of the Minister of Health of the Republic of Indonesia Number 45 of 2014 on Extraordinary Events. Outbreaks are a condition of increased incidence of morbidity or mortality that is epidemiologically significant in a population in a particular area over a certain period of time that is feared will lead to an outbreak. Despite 
the differences in conditions with this study, it is important to note the similarity in the factors that influence, the cause or the source.

In outbreaks of food, poisoning investigations have shown contamination from the hands of inadequately clean food handlers so that they are a source of pathogenic causes of food poisoning [11]. Food handlers are a risk that significantly causes the spread of enteric fever infection in Kumasi. This can be even worse with food poisoning in cities where food handlers have low food safety knowledge [36]. In addition to the habits of people who have a low awareness of food, hygiene increases the risk of food poisoning. The result of research of Saba (2012), fruits are food that is at risk of poisoning because people consume fruit without heating process and usually the process of washing less clean [36].

So as a preventive effort needs to be done storage, processing, and serving right and adequate of the food. Storage separately on raw food and cooked foods, processing with the right temperature and immediately eating the food served will reduce the risk of food poisoning. The purpose of adequate food processing is to reduce the number of pathogenic organisms such as bacteria or viruses so that the pathogenic organism is reduced and does not cause food poisoning [41].

Temperature distribution and heating in foods also affect the growth of bacteria in food. As Tavakoli et.al (2009) in his research aimed to evaluate the bacteria, chemicals, and quality of cooked food with traditional and modern equipment shows that high-temperature cooking can effectively reduce contamination. But of course, also need to note the nutritional content in the food so that it is not damaged by the temperature is too high [42].

In addition to the data collection of food poisoning cases there should also be variable data on the types of diseases and pathogens that cause food poisoning such as the research conducted by Osei-tutu (2016) in Ghana, Aboderin and Bankole (2009) in Nigeria, Pardhan-Ali (2017) in Canada, Adak (2017) in the UK, Scallan (2007), Gumbo (2015) in Zimbabwe, Wang (2007) in China and Kirk (2014) in Circa. It certainly will be very useful to determine prevention efforts that will be implemented both from the clinical aspects and preventive promotive.

There should also be cooperation between surveillance, laboratory examination of food samples, stools or other samples and food inspection bodies for food poisoning prevention efforts. In Indonesia, INADFC is a body tasked to monitor food security, but in the implementation of food poisoning surveillance system itself has not run optimally. This is because the implementation of food poisoning surveillance has no binding regulation resulting in the reporting of food poisoning data voluntarily by hospitals, including hospitals in DKI Jakarta. Voluntary reporting tends to cause some hospitals to be reluctant to report cases of food poisoning so there may be cases in the community that are not recorded in the National BPI - RI Siker case report. The absence of regulation also affects the weak laboratory role so that biological and chemical checks are not conducted.
According to Malangu, not all countries have a laboratory to determine the contaminants in the food poisoning cause and there are some countries also have a laboratory but the role has not been able to run optimally. This is due to lack of human resources, natural resources, and financing. As is the case in Africa where human resource competence is limited in the testing of chemicals as well as natural toxins that contaminate food [26]. Limitations of these capabilities can certainly disrupt laboratory-based surveillance systems.

So in overcoming the problem is expected INADFC can coordinate with provincial INADFC to conduct the direct investigation on the patient of food poisoning in hospital. And build an active communication with the hospital so that any cases of food poisoning can be reported to INADFC. Through the investigation is also expected to conduct inspection or laboratory tests on samples needed to determine the type of pathogen or certain chemicals as a cause of food poisoning.

\section{E. Sources of Food Poisoning}

food poisoning in DKI Jakarta in 2016 comes from households with a proportion of $45.7 \%$. And the same thing happened in the age group that has the opal immunity, female gender, and the dry season that many food poisonings comes from the household with the proportion of $44.27 \%, 45.8 \%$, and $45.7 \%$.

This study is similar to studies in China and Ontario where households are a major source of food poisoning with a proportion of $24.4 \%$ of 2387 new cases and $40.1 \%$ [21, 43]. In this study households as a source of food poisoning were defined as an individual residence or a group of specific individuals who had a private kitchen and food processing as well as food presentation performed on that household which could potentially lead to food poisoning [41].

Inside the household consists of families that are the smallest communities in the consumer group that have a strong attachment to one and the other. In addition, the house is a place that has a variety of functions that either directly or not affect the health status of its inhabitants, especially diseases caused by food.

In this study, the types of food that cause food poisoning in households are seafood and fish - fish with a proportion of $60.4 \%$. Seafood and fish - this is a complex source of nutrients affordable for consumption by people with different socioeconomic levels. But it can be a potential cause of food poisoning because in processing seafood and fish - the fish, food handlers ignore the storage, processing or adequate presentation. The use of contaminated water for cleaning or cooking also affects the types of pathogens present in the food. water that is clean and feasible for consumption is water that does not contain coliform that is known through the laboratory test.

Personal hygiene poor food handlers such as the behavior of not washing hands before and after meals or touching food, after using the toilet, contact with others, play with pets or other also determine a person's risk for food poisoning. Many organisms can be found in the environment. Especially pets that not have the ability to clean themselves can 
be a source of pathogens for the owner. The people of DKI Jakarta, which is a modern society also has a penchant for maintaining certain animals in the home such as cats, dogs or other types of reptiles. However, in this study, there are no supporting data related to this matter.

The existence of these assumptions is supported by previous research where the use of contaminated water, personto-person contact by family members or other unidentified sources may be the cause of food poisoning [43]. As well as in pets at homes such as cats and $\operatorname{dogs}$ can be found Campylobacter [44].

There are also other studies that have different results, as has been done in Qatar where food poisoning occurs in open events (42.2\%), kitchen (23.1\%), school $(0.1 \%)$ and others (34.6\%) [4]. In China, food poisoning is caused by bacteria due to food consumption provided by food service providers such as catering, restaurant or food stalls with the proportion of $31.05 \%$, and processed food products of $26.25 \%$ [31]. And other studies also indicate the types of food that may cause food poisoning in the household are raw meat and poultry, eggs, unpasteurized milk and raw fish [41].

While other sources and unknown sources tend to have low proportions. Other sources are food sources originating from households, catering and street vendors. Thus included in other sources are from schools, markets, food industries and others. Whereas unknown sources of food poisoning are caused by health workers in hospitals who do not complete the medical records of cases of poisoning in the ER. In addition, patients who forgot or did not know the type of food consumed for several hours until the last few days. Therefore health workers are advised to keep digging the source of food poisoning information to family members or friends who are accompanying and there when victims are eating food.

Basically, food poisoning can occur in all laces where food is stored, processed and prepared. However, based on this study, households as the main source of food poisoning are the main target in receiving food poisoning prevention interventions, especially mothers or women who are the main food handlers. So it is necessary to adjust the media so that prevention messages can be accepted by the community.

\section{CONCLUSIONS}

The proportion of food poisoning in DKI Jakarta in 2016 is greater in the age group which has the optimal immunity of $92.3 \%$ and female gender is $51.4 \%$. Inaddition, food poisoning occurred in the dry season with the proportion of $62 \%$ with the type of food that causes the biggest food poisoning is seafood and fish - fish with a proportion of $52.4 \%$. The source of food poisoning that causes food poisoning is a household that is $45.7 \%$. whereas in the analysis using multinomial logistic regression test, only sexes were associated with other food poisoning sources ( $\mathrm{P}$ value $<0.05$ ). The the advice given to INADFC is to coordinate with the provincial INADFC to conduct an investigation into cases of active food poisoning that occurred in the hospital. With this effort, it is expected that the laboratory examination of the collected sample can also be done. So that can be known the type of pathogen or chemical substances that cause food poisoning. as well as the need for prevention of food poisoning in the form of counseling food poisoning to families, especially mothers. This will have a major impact in accelerating the delivery of information to individuals or families in the surrounding environment. In addition, the mother has a central role in ensuring food hygiene and safety to his family.

\section{ACKNOWLEDGMENT}

The authors would to thank the various parties who have helped in this research:RatriCIptaningtyas, MHS.,Faculty of Medicine and Health Science UIN SyarifHidayatullah Jakarta and Indonesian National Agency Drug and Food Control.

\section{REFERENCES}

[1] Mutalib ea. An Overview of Foodborne Ilness and Food Safety in Malaysia. International Food Research Journal. 2014;22[3].

[2] WHO. WHO's first ever global estimates of foodborne diseases find children under 5 account for almost one third of deaths 2015 [cited 20177 February ]. Available from: http://www.who.int/mediacentre/news/releases/2015/foodborne-diseaseestimates/en/.

[3] Sifferlin A. 351,000 People Die of Food Poisoning Globally Every Year. 2015.

[4] Ahmed A, et.al. Poisoning Emergency Visits among Children : a 3 Years Retrospective Study in Qatar. BMC Pediatric. 2015;15(104):7.

[5] Linscott AJ. Food-borne Ilnesses. Clinical Microbiology Newspaper. 2011.

[6] Campos AKC, et all. Assessment of Personal Hygiene and Practices of Food Handlers in Municipal Public Schools of Natal, Brazil. 2009;20:80710.

[7] Malangu N. Risk Factors and Outcomes of Food Poisoning in Africa. Agricultural and Biological Sciences. 2016;978-953-51-2277-7.

[8] Kirk MDea. Foodborne Disease in Australia: The OzFoodNet Experience. Clinical Infectious Disease 2008.

[9] Gumbo Aea. Staphyilococcus Aureus Food Poisoning Among Bulawayo City Council Employees, Zimbabwe, 2014. BMC Research Notes. 2015.

[10] Teschke Kea. Water and Sewage Systems, Socio-demographics, and Duration of Residence Associated with endemic Intestinal Infectious Diseases: A Cohort Study. BMC Public Health. 2010;10 : 767:1471-2458.

[11] Abd-ELhaleem ZAdA-E. Pattern of Food Poisoning in Egypt, a Retrospective Study. Journal of Pharmacology and Toxicology 2011;5:505-15.

[12] Majowicz SEea. Magnitude and Distribution of Acute, Self-Reported Gastrointestinal Illness in Canadian Community. Epidemiol Infect. 2004;(2004, 132):607-17.

[13] Kariuki S. Typhoid Fever in sub-Saharan Africa: Challenges of Diagnosis and Management of Infections. Regional Review Aricle. 2008;2 [6]:443-7.

[14] Painter JA, et.al. Attribution of Foodborne Illnesses, Hospitalizations, and Deaths to Food Commodities by using Outbreak Data, United States, 1998-2008. Emerging Infectious Diseases. 2013;19, No. 3, March 2013.

[15] Glasgow LM, et.al. Estimating the Burden of Acute Gastrointestinal Illness in Grenade. J Health Popul Nutr. 2013;31 Number 4 (Suppl I) ;S17S29:12.

[16]Pardhan-Ali Aea. A Descriptive Analysis of Notifiable Gastrointestinal Illness in The Nortwest Territories, Canada 19910 2008. BMJ Journal. 2017.

[17] Scott E. Foodborne Disease and Other Hygiene Issues in the Home. Journal of Applied Bacteriology. 1996;80:5.

[18] Shiferaw B, et.al. Sex-Based Differences in Food Consumption: Foodborne Diseases Active Surveillance Network (FoodNet) Population Survey, 2006-2007. Clinical Infectious Diseases. 2012;54(suppl_5,):S453-S7.

[19]Bloomingdale A, et.al. A qualitative study of fish consumption during pregnancy. The American Journal of Clinical Nutrition. 2010;92 [5] 1234 40 . 
[20] Indranil Pa. Food Poisoning: Illness Ranges from Relatively Mild Through To Life Threatening. Journal of Medical and Health Science. 2016;5[4].

[21] Xue JdWZ. Understanding China's food safety problem: An analysis of 2387 incidents of acute foodborne illness. Elsevier Science. 2011;30 (2013):7.

[22] Vemula SRea. Emerald Article: Foodborne diseases in India - a review. British Food Journal. 2012;114 Iss: 5 pp:661 - 80.

[23] N A, Ohta M and Yokoyama K. Production of Bacillus cereus emetic toxin (cereulide) in various foods. 73 [1]: 23 - 7. 2002.

[24]Ehling-Schulz M, et.al. Identification of emetic toxin producing Bacillus cereus strains by a novel molecular assay. FEMS Microbioloy Letters. 2004;232[2]:189 - 95.

[25] Mensah Pea. Street foods in Accra, Ghana: how safe are they? Bulletin of the World Health Organization. 2002;8 [7].

[26] Malangu N. Risk Factors and Outcomes of Food Poisoning in Africa: Intech.

[27] Courtney S, et.al. Food safety knowledge of undergraduate students at a Canadian university: results of an online survey. BMC Public Health. 2016;16.

[28] Unusan N. Consumer Food Safety Knowledge and Practices in the Home in Turkey. Elsevier. 2005:7.

[29] lake IR, et.al. A Re-evaluatio of the Impact of Temperature and Climate Change on Foodborne Illness. Epidemiol Infect. 2009;137:10.

[30]Bi P, et.al. Weather and Notified Campylobacter Infections in Temperate and sub-Tropical Regions of Australia: An Acological Study. Journal of Infection : Elsivier. 2008;57:317 - 23.

[31] Wang S, et.al. Analysis of Bacterial Foodborne Disease Outbreaks in China Between 1994 and 2005. FEMS Immunol Med Microbial. 2007;51 (2007):8-13.

[32] Sousa CPd. The Impact of Food Manufacturing Practices on Food borne Diseases. Brazilian Archies of Biology and Technology. 2008;51:9.

[33]CDC. Food Safety : Keep Food Safe 2017 [cited 201709 October]. Available from: https://www.cdc.gov/foodsafety/keep-food-safe.html.

[34] Iwamoto M, et.al. Epidemiology of Seafood-Associated Infections in the United States. Clinical Microbial Reviews. 2010;23 [2]:12.

[35]HP. Scientific Committee on Enteric Infections and Foodborne Diseases Foodborne illness - Intersection between Clinical and Public Health Approaches: Centre of Health Protection; s.a.

[36] Saba Courage KSdBG-Z. Microbial Food Safety in Ghana : a Metaanalysis. Emerging Problems in Infectious Deseases. 2012;6 [12]:828-35.

[37] EK LaRJ. The Role of Seafood in Foodborne Disease in The United States of America. Rev Sci Tech. 1997;2:620 - 40.

[38] Stratta PaGB. Scombroid poisoning. Canadian Medical Association Journal. 2012;184 [6].

[39] CDC. Harmful Algal Blooms (HABs) [cited 20174 October ]. Available from: https://www.cdc.gov/nceh/ciguatera/.

[40] Maruyama K, et.al. Methyl Mercury Exposure at Niigata, Japan: Results of Neurological Examinations of 103 Adults. Journal of Biomedicine and Bioetechnology. 2012;2012:7.

[41] IFH. Foodborne disease and the home. 2014.

[42] R Mea. Hygienic quality of food stuff in catering services and restaurants in Iran. International Food Research Journal. 2013;21 [2]:673 - 6.

[43] Greig JD, et.al. A Descriptive Analysis of Giardiasis Cases Reported in Ontario, 1990 - 1998. Canadian Journal of Public Health. 2001;September - October 2001

[44] Scott E. Food Safety and Foodborne Disease in 21st Century Homes. Stainer Review. 2003;14[5]:277-80. 